\title{
Sexual behavior and knowledge of human immunodeficiency virus/aids and sexually transmitted infections among women inmates of Briman Prison, Jeddah, Saudi Arabia
}

\author{
Wafa MK Fageeh
}

\begin{abstract}
Background: To reduce the incidence of HIV and sexually transmitted infections (STIS), it is necessary to target high-risk populations such as prison inmates. This study aims to explore the range of knowledge on HIV and STIs, sexual behaviors, and adoption of preventive measures among women inmates.

Methods: This was a survey conducted between July 1, 2012 and July 29, 2012 among women inmates at Briman Prison, Jeddah, Saudi Arabia. The author gave an educational lecture on STIs in a conference room at the prison. Educational material was distributed to the attendees after the lecture, and the survey was conducted one week later. All the participants were asked to complete an anonymous 40-item self-administered questionnaire in the presence of a professional health assistant and a translator, for non-Arabic speakers. Data collected included the personal data of the respondent, her alleged criminal background, penal status, accumulative time in prison, history of smoking, alcohol or drug addiction, knowledge about the seven most common STIs, symptoms, modes of transmission, prevention, sexual activity, addiction, and means of protection. Descriptive analysis was performed using Microsoft Excel.
\end{abstract}

Results: We interviewed 204 women aged 16-60 years (mean, 33.3 years). Most of the respondents ( $n=170 ; 83 \cdot 0 \%)$ were not aware of STIs; 117 respondents (57.4\%) did not undergo screening for STIs before marriage or intercourse, while only $59(28 \cdot 9 \%)$ did. Over half of the respondents $(n=107 ; 52.5 \%)$ thought they knew how to protect themselves from STIs. Nevertheless, 87 (42.6\%) were uncertain about the role of condoms in protection from STIs and $(n=41$; 20.1\%) thought condoms provide 100\% protection against STIs, while 72 respondents (35.3\%) thought condoms did not confer $100 \%$ protection against STIs. Only 10 respondents (4.9\%) used condoms to protect themselves from STIs. Saudi women $(P=0.033)$ and those with a higher level of education $(P<0.01)$ were significantly more likely to have better knowledge.

Conclusion: Women inmates at Briman Prison have poor knowledge of STIs as well as risky sexual behaviors. Campaigns aimed at increasing awareness of STIs should also target prison inmates, who in general constitute high-risk populations.

\section{Background}

Over the recent years, there has been an increase in the spread of human immunodeficiency virus (HIV) infection and other sexually transmitted infections (STIs) in many countries [1]. Because of the stigma associated with these infections, multiple barriers to testing and treatment exist, mainly in conservative communities. In order to fight the

Correspondence: fageeh.wafa@gmail.com

Department of Obstetrics and Gynecology, King Abdulaziz University, King Abdullah Road, PO Box 80215, Jeddah 21589, Saudi Arabia spread of HIV and STIs, many countries have adopted different modalities to improve awareness. Campaigns have proven effective in achieving better awareness, increasing health-seeking behavior, testing for STIs, and HIV/STI knowledge [2].

To reduce the incidence of HIV and STIs, it is necessary to target high-risk populations such as prison inmates. More so, interventions among prison inmates may provide an opportunity to reach high-risk populations and prevent the wider spread of sexually transmitted HIV [3]. In conservative countries, the lack of education on sexual 
health has made it increasingly difficult to prevent the spread of STIs [4], both in the general population and in at-risk persons.

Very few studies focusing on knowledge and awareness of STIs have been conducted in both adolescents and adults in Saudi Arabia [5,6]. According to findings from a report that evaluated awareness of sexually transmitted infections (STIs) among Saudi adolescents, most respondents were superficially aware of STIs, and had incorrect perceptions about the mode of transmission and means of protection [4]. This study was designed to explore the range of knowledge on HIV and STIs, sexual behaviors, and adoption of preventive measures among women inmates at Briman Prison, Jeddah.

\section{Methods}

We conducted a survey between July 1, 2012 and July 29, 2012 among women inmates who were detained at Briman Prison, Jeddah. The Institutional Review Board of the Ministry of Health (Western Province, Saudi Arabia) provided ethical review for the survey, including voluntary recruitment, strict confidentiality provisions, and informed consent.

The author gave an education lecture to nearly 300 women prisoners at a conference room in Briman Prison. Educational material was distributed to the attendees at the end of the lecture. The author clearly explained that participation in the survey was completely voluntary, and it was limited to those who were interested. The survey was conducted one week later to allow time for the women to think about participating. Of the 300 women who attended the lecture, only 201 decided to participate, representing a response rate of $67 \%$.

Participants were informed that they were not obliged to answer any question if they were not comfortable answering it. The prison supervisor was not present in the section allocated for our study so as to prevent any feeling of pressure on the participants, who were actually discouraged by the prison administration from participating. Participants were asked to complete a questionnaire in the presence of a professional health assistant and a translator, for non-Arabic speakers. The interviewers explained the purpose of the research to all participants, who were asked to fill a 40-item questionnaire. Special assistance was provided to the illiterate. The questionnaire was developed in Arabic by selecting items based on expert opinion, taking into account the subjective perception of the respondents' knowledge of STIs. The questionnaire was divided into six sections. (1) Personal data of the respondent, including educational status, marital status, financial situation, and means of support. (2) The alleged criminal background of the respondent, penal status, accumulative time in prison. (3) Sexual activity and smoking, alcohol or drug addiction (4) Knowledge about the seven most common STIs (human immunodeficiency virus, herpes simplex virus type 2 , human papilloma virus, syphilis, chlamydia, gonorrhea, and hepatitis B virus), symptoms, modes of transmission, complications, prognosis, treatment, and prevention. (5) Source of information (6) Protection against STIs, analysis of condom usage, and actions taken if partner acquired one of the STIs. The questionnaire questions are presented below:

- 1-Age, 2-Gender, 3-Ethnicity, 4-Religion, 5-Number of children

- 6-Mode of Living (1-apartment rented 2- apartment owned 3-rented villa 4- villa owner)

- 7-Educational attainment (1-uneducated 2-primary education 3-secondary education 4- college graduate)

- 8- Marital status/number of previous marriages/ relationships?

- 9-What were you convicted of? What is your penal status?

- 10- Do you work?

- 11-Does your husband work?

- 12- Are you financially dependent on your husband?

- 13-Have you undergone premarital checkup?

- 14-Do you smoke?

- 15-Do you drink alcohol?

- 16-Do you use drugs? If YES, specify: Rush, Hashish, Captagon, Heroin, Logga, Powder, Cocaine, Amphetamine, Chewing tobacco (noshog), Morphine, Sniffing glue (Ghera'a)

- Do you know the mode of transmission of the following infections?

17-HSV, 18-HPV, 19-SYPHILLIS, 20-GONORRHEA, 21- CHLAMYDIA, 22-HIV, 23-HEPATITS-B, 24-HIV

- 25-Is there a vaccine to protect you against ALL STIs?

- Do you know the clinical presentation of these infections?

26- Herpes simplex virus? (1-warts 2-ulcers

3 -vaginal discharge 4-papules 5-I don't know)

27- Human papilloma virus? (1-warts 2-ulcers

3-vaginal discharge 4-papules 5-I don't know)

- 28-What is your source of information?

TV/Radio, Internet, Books, Magazines/Newspaper, Friends, Family, Others

- 29-Do you know how to protect yourself from STIs?

- 30 -Do you think condoms are $100 \%$ protective against STIs?

- 31-Would you like to know if you already acquired any STIs?

- 32-Do you think you have the right to know if your husband has any STIs?

- 33-What will you do if you found out your husband has acquired one of the STIs? 
- 34- ask for divorce, 35- ask him to seek medical advice, 36- seek medical advice, 37- will not do anything, 38- will refrain from sexual intercourse, 39- not sure

- 40-Do you think you should consider studying these infectious diseases in school or during secondary education?

\section{Statistical analysis}

A simple descriptive statistics was performed to show the frequency distributions, mean, range and variations using Microsoft Excel $2007^{\circ}$. Chi-square test was used to establish a relationship between two categorical variables. To measure the knowledge, a mean score was calculated from a number of criterion and measures were grouped into two categories. Lastly, a conventional $\mathrm{p}$-value $<0.05$ was used to reject null hypothesis.

\section{Results}

We interviewed 204 women prisoners aged 16-60 years (mean, 33.3 years \pm 9.3 years). Most of the respondents were convicted for prostitution ( $\mathrm{n}=105 ; 51.4 \%)$, followed by illegal immigration $20(9.8 \%)$ and wine trading $(n=14$; $6.8 \%)$; adultery, begging, and murder were less frequent reasons for incarceration (Table 1). Of the 204 respondents, there were 65 Indonesians (31.9\%), 35 Somalis (17.2\%), 32 Ethiopians (15.7\%), and 16 Saudis (7.8\%); the remaining 56 respondents were from neighboring countries. Regarding marital status, 80 women (39.2\%) were married, 62 (30.4\%) were single, 43 (21.0\%) were divorced and $19(9.3 \%)$ were widows. $70(34.3 \%)$ of the respondents were illiterate; $67(32.9 \%)$ had completed secondary education, while $56(27.5 \%)$ had only completed primary education. Only 10 (4.9\%) were college graduates. One respondent did not reveal her level of education. Among the respondents, 146 (71.5\%) were working prior

Table 1 Offences Committed by the respondents

\begin{tabular}{ll}
\hline Type of crime & Number of prisoners \\
\hline Prostitution & $105(51.4 \%)$ \\
Wine trading & $14(6.8 \%)$ \\
Forgery, blackmail, theft & $10(4.9 \%)$ \\
Witchcraft & $2(0.9 \%)$ \\
Fighting & $7(3.4 \%)$ \\
Drug dealing & $8(3.9 \%)$ \\
Illegal immigration & $20(9.8 \%)$ \\
Financial matters/debt & $4(1.9 \%)$ \\
Adultery & $9(4.41 \%)$ \\
Murder & $5(2.4 \%)$ \\
Begging & $5(2.4 \%)$ \\
Others & $15(7.3 \%)$ \\
\hline
\end{tabular}

to imprisonment, whereas 81 (39.7\%) were financially dependent on their partners.

Thirty-eight respondents (18.6\%) were smokers, with no history of alcohol addiction. A history of drug abuse was recorded in 4 respondents $(1.9 \%)$.

While 117 respondents (57.4\%) reported that they did not undergo screening for STIs before marriage or sexual intercourse, 59 (28.9\%) reported they did; 28 respondents (13.7\%) declined to respond. Over half of the respondents $(\mathrm{n}=107 ; 52.5 \%)$ thought they knew how to protect themselves from STIs, while $92(45.1 \%)$ reported having no knowledge on protective methods. 3 respondents (1.5\%) were uncertain, while 5 (2.4\%) declined to respond.

One in five of the respondents $(n=41 ; 20 \cdot 1 \%)$ thought condoms provide $100 \%$ protection against STIs. Eightyseven $(42.6 \%)$ were uncertain about the role of condoms in protection from STIs while 72 respondents (35.3\%) thought condoms did not confer $100 \%$ protection against STIs. 4 (2.0\%) respondents declined to give their opinion on the use of condoms. Only 10 respondents (4.9\%) reported they used condoms to protect themselves from STIs, while $31(15.2 \%)$ reported they have used it for contraceptive purposes. Only 3 out of the 31 women who used condoms for contraceptive purposes have used it for protection from STIs as well. Nineteen women (9.3\%) declined to respond.

Most of the respondents $(n=170 ; 83 \cdot 0 \%)$ were not aware of STIs. Friends, television, and radio programs were the major sources of information $(n=60 ; 29.4 \%$, in each case). Other sources of information included family members $(n=46 ; 22.5 \%)$, newspapers and magazines $(n=22 ; 10 \cdot 8 \%)$, books $(n=20 ; 9.8 \%)$, and the Internet $(\mathrm{n}=20 ; 9 \cdot 8 \%)$. Only 20 respondents $(9 \cdot 8 \%)$ mentioned other less common sources of information.

Women with a higher the level of education were significantly more likely to have better knowledge about STIs (P-value <0.001; Table 2). Saudi women also seemed to have better knowledge than expatriate women $(P=0.033)$. Table 2 demonstrates the effect of different variables on the level of awareness. Their level of knowledge was considered to be good if they scored $\geq 50 \%$ and poor if they scored $<50 \%$ (Tables 3 and 4 ).

Over half of the respondents $(n=159 ; 77.9 \%)$ reported they would want to know whether they had any of the STIs. 172 respondents $(84.3 \%)$ thought they had the right to know if their spouses had an STI; $180(88 \cdot 2 \%)$ believed their spouses had the right to know if they had an STI. When asked about their reaction to a spouse testing positive for any of the STIs, 181 respondents $(88 \cdot 7 \%)$ responded they would ask their spouses to seek medical advice, 67 $(32 \cdot 8 \%)$ reported they would file for divorce, and only 66 (32 - 4\%) responded they would seek medical check-up.

Regarding the respondents' opinion about awareness and prevention of STIs, $31(15 \cdot 2 \%)$ responded that this 
Table 2 Correlation between different variables and level of awareness about sexually transmitted infections

\begin{tabular}{|c|c|c|c|c|c|c|c|}
\hline & \multicolumn{2}{|l|}{ Variables } & \multicolumn{2}{|c|}{ Knowledge group } & \multirow[t]{3}{*}{ Total } & \multirow[t]{3}{*}{$x^{2}$} & \multirow[t]{3}{*}{ P-value } \\
\hline & & & $<50 \%$ & $\geq \mathbf{5 0 \%}$ & & & \\
\hline & & & Correct & Correct & & & \\
\hline \multirow[t]{4}{*}{ Age } & $\leq 30$ & Count & 91 & 7 & 98 & 1.510 & 0.219 \\
\hline & & $\%$ & $92.9 \%$ & $7.1 \%$ & $100.0 \%$ & & \\
\hline & $>30$ & Count & 93 & 13 & 106 & & \\
\hline & & $\%$ & $87.7 \%$ & $12.3 \%$ & $100.0 \%$ & & \\
\hline \multirow[t]{2}{*}{ Total } & & Count & 184 & 20 & 204 & & \\
\hline & & $\%$ & $90.2 \%$ & $9.8 \%$ & $100.0 \%$ & & \\
\hline \multirow[t]{4}{*}{ Nationality } & Saudi & Count & 12 & 4 & 16 & 4.534 & $0.033^{*}$ \\
\hline & & $\%$ & $75.0 \%$ & $25.0 \%$ & $100.0 \%$ & & \\
\hline & Non-Saudi & Count & 172 & 16 & 188 & & \\
\hline & & $\%$ & $91.5 \%$ & $8.5 \%$ & $100.0 \%$ & & \\
\hline \multirow[t]{2}{*}{ Total } & & Count & 184 & 20 & 204 & & \\
\hline & & $\%$ & $90.2 \%$ & $9.8 \%$ & $100.0 \%$ & & \\
\hline \multirow[t]{4}{*}{ Religion } & Islam & Count & 174 & 18 & 192 & 1.584 & 0.208 \\
\hline & & $\%$ & $90.6 \%$ & $9.4 \%$ & $100.0 \%$ & & \\
\hline & Christian & Count & 7 & 2 & 9 & & \\
\hline & & $\%$ & $77.8 \%$ & $22.2 \%$ & $100.0 \%$ & & \\
\hline \multirow[t]{2}{*}{ Total } & & Count & 181 & 20 & 201 & & \\
\hline & & $\%$ & $90.0 \%$ & $10.0 \%$ & $100.0 \%$ & & \\
\hline \multirow[t]{8}{*}{ Marital status } & Single & Count & 54 & 8 & 62 & 7.199 & 0.066 \\
\hline & & $\%$ & $87.1 \%$ & $12.9 \%$ & $100.0 \%$ & & \\
\hline & Married & Count & 69 & 11 & 80 & & \\
\hline & & $\%$ & $86.3 \%$ & $13.8 \%$ & $100.0 \%$ & & \\
\hline & Divorced & Count & 43 & 0 & 43 & & \\
\hline & & $\%$ & $100.0 \%$ & $0.0 \%$ & $100.0 \%$ & & \\
\hline & Widowed & Count & 18 & 1 & 19 & & \\
\hline & & $\%$ & $94.7 \%$ & $5.3 \%$ & $100.0 \%$ & & \\
\hline \multirow[t]{2}{*}{ Total } & & Count & 184 & 20 & 204 & & \\
\hline & & $\%$ & $90.2 \%$ & $9.8 \%$ & $100.0 \%$ & & \\
\hline \multirow[t]{4}{*}{ Housing } & Rental & Count & 162 & 16 & 178 & 1.398 & 0.237 \\
\hline & & $\%$ & $91.0 \%$ & $9.0 \%$ & $100.0 \%$ & & \\
\hline & Owned & Count & 20 & 4 & 24 & & \\
\hline & & $\%$ & $83.3 \%$ & $16.7 \%$ & $100.0 \%$ & & \\
\hline \multirow[t]{2}{*}{ Total } & & Count & 182 & 20 & 202 & & \\
\hline & & $\%$ & $90.1 \%$ & $9.9 \%$ & $100.0 \%$ & & \\
\hline \multirow[t]{6}{*}{ Educational attainment } & Primary or below & Count & 122 & 4 & 126 & 36.582 & $<0.001^{*}$ \\
\hline & & $\%$ & $96.8 \%$ & $3.2 \%$ & $100.0 \%$ & & \\
\hline & Secondary & Count & 57 & 10 & 67 & & \\
\hline & & $\%$ & $85.1 \%$ & $14.9 \%$ & $100.0 \%$ & & \\
\hline & University & Count & 4 & 6 & 10 & & \\
\hline & & $\%$ & $40.0 \%$ & $60.0 \%$ & $100.0 \%$ & & \\
\hline \multirow[t]{2}{*}{ Total } & & Count & 183 & 20 & 203 & & \\
\hline & & $\%$ & $90.1 \%$ & $9.9 \%$ & $100.0 \%$ & & \\
\hline
\end{tabular}


Table 2 Correlation between different variables and level of awareness about sexually transmitted infections (Continued)

\begin{tabular}{lcccccc}
\hline Employment status & Yes & Count & 132 & 14 & 146 & 0.027 \\
& & $\%$ & $90.4 \%$ & $9.6 \%$ & $100.0 \%$ & 0.870 \\
& No & Count & 52 & 6 & 58 & \\
Total & $\%$ & $89.7 \%$ & $10.3 \%$ & $100.0 \%$ & \\
& & Count & 184 & 20 & 204 & $100.0 \%$ \\
\hline
\end{tabular}

*Significant using chi-square test $>0.05$ level.

information should be taught in primary or secondary school.

\section{Discussion}

This study is novel in that it is the first to explore the sexual behaviors and degree of knowledge about STIs among women prisoners in Saudi Arabia. Our findings revealed that women inmates had poor knowledge of STIs, which could explain their risky sexual behaviors. Over half of the respondents had never undergone screening for STIs before marriage or sexual intercourse, and up to 92 respondents (45.1\%) had no knowledge on how to protect themselves from STIs. In addition, 41 $(20 \cdot 1 \%)$ of the respondents in our study believed that condoms gave $100 \%$ protection against STIs, and 87 $(42 \cdot 6 \%)$ were unsure of their protective effect.

Contrary to reports from other authors who reported that $44.0 \%$ of the respondents in their study used condoms consistently [7], we found that only $10(4.9 \%)$ of the respondents in our study used condoms for protection against STIs and $31(15 \cdot 2 \%)$ used them for contraceptive purposes. However, this observation could be due to the fact that up to $39.2 \%$ of the respondents in our study group were married and $51.5 \%$ were allegedly incarcerated for prostitution. There are reports that sex workers generally have high-risk sexual behaviors, and the consumption of alcohol prior to sex among migrant female sex workers has been reported to be significantly associated with inconsistent condom use during paid or unpaid sex [8]. We did not, however, have any report of alcohol consumption among the respondents in our study, and other factors, such as poor knowledge may explain the low use of condoms among the women.

Clinical studies on the effectiveness of condoms against most STIs suggest inconsistent levels of protection. Studies show varied rates of reduction of HIV transmission in

Table 3 Scoring system regarding level of knowledge

\begin{tabular}{llrr}
\hline Variables & & Frequency & Percent \\
\hline Knowledge group & $<50 \%$ correct & 184 & 90.2 \\
& $\geq 50 \%$ correct & 20 & 9.8 \\
& Total & 204 & 100.0 \\
\hline
\end{tabular}

association with condom use. Some advocate the reduction rate of HIV transmission related to condom use by $87 \%$ [9]; however, others found that the reduction rate is only $30 \%$ in HIV-2 [10]. This is mainly because a condom's primary role is to create a barrier between sexual fluids. This largely decreases the chances of transmission of STIs that are fluid mediated but can do little against the ones that are transmitted through skin to skin contact or skin to mucosa contact such as HIV-2, human papilloma virus and herpes simplex-2. This is not to say that the use of condoms as a means of protection should be overlooked; however, it is not a foolproof solution. The best prevention method is to refrain from risky sexual activities.

Despite the fact that uneducated women accounted for only $34 \cdot 3 \%$ of our study sample, and $32.9 \%$ had completed at least secondary education, most of the women had risky sexual behaviors. Studies on adults show that there are inconsistent findings on the association between education and sexual risk [11]. In another study involving a sample of incarcerated women aged $\geq 18$ years, it was reported that women with more years of education were less likely to engage in risky sexual behaviors, such as having unprotected sex compared with their less educated peers [12]. This contradicts the findings of a meta-analysis that encompassed 28 countries both within and outside of Africa, which demonstrated a rather high prevalence of higher-risk sexual behavior among the wealthier and more educated women. This finding was inspite of the geographic location of the selected low to middle income countries [13].

In Saudi Arabia, there is limited data on STIs. In addition to the fact that many people with STIs are asymptomatic and cases remain undiagnosed, those that are diagnosed are frequently not reported. Underreporting of STIs is not only a problem in Saudi Arabia; it is common in other developed countries as well $[14,15]$. It is also frequent among female sex workers, mainly due to unawareness of the symptoms of STIs (including asymptomatic STI) and their belief that they are at low-risk for STIs [15]. In our study, $20 \%$ of the respondents did not want to know whether they had an STI, which is a relatively high percentage for a high-risk group. Nearly 
Table 4 Level of knowledge on the seven sexually transmitted infections

\begin{tabular}{llrr}
\hline Knowledge variables & & Frequency & Percent \\
\hline Symptoms of herpes simplex virus & Correct & 13 & 6.4 \\
& Incorrect & 191 & 93.6 \\
& Total & 204 & 100.0 \\
Symptoms of human papilloma virus & Correct & 4 & 2.0 \\
& Incorrect & 200 & 98.0 \\
& Total & 204 & 100.0 \\
Do you think condoms provide & Correct & 72 & 35.3 \\
100\% protection against sexually & Incorrect & 132 & 64.7 \\
transmitted infections? & Total & 204 & 100.0
\end{tabular}

Do you think the following infections are transmitted by sexual contact? Herpes simplex virus $\begin{array}{lll}\text { Correct } & 24 & 11.8\end{array}$

\begin{tabular}{llrr} 
& Incorrect & 180 & 88.2 \\
& Total & 204 & 100.0 \\
Human papilloma virus & Correct & 18 & 8.8 \\
& Incorrect & 186 & 91.2 \\
& Total & 204 & 100.0 \\
Syphilis & Correct & 26 & 12.7 \\
& Incorrect & 178 & 87.3 \\
Gonorrhea & Total & 204 & 100.0 \\
& Correct & 19 & 9.3 \\
& Incorrect & 185 & 90.7 \\
Chlamydia & Total & 204 & 100.0 \\
& Correct & 15 & 7.4 \\
& Incorrect & 189 & 92.6 \\
Human immunodeficiency virus & Total & 204 & 100.0 \\
& Correct & 91 & 44.6 \\
& Incorrect & 113 & 55.4 \\
& Total & 204 & 100.0 \\
& Correct & 21 & 10.3 \\
Hepatitis B virus & Incorrect & 183 & 89.7 \\
& Total & 204 & 100.0 \\
\hline & & &
\end{tabular}

nine out of ten respondents reported they believed that they had the right to know if their partners had an STI. A similar percentage believed their partners had the right to know if they were infected. This might reflect either honesty or lack of understanding on the part of the respondents about the mode of transmission of STIs. When asked about their reaction to a spouse testing positive for any STI, nine out of ten respondents responded that they would ask the partner to seek medical advice, while only one third responded that they would have medical checkup. This as well also reflected deficient knowledge on specific STIs and their respective symptoms, the mode of transmission, and consequences. This lack of awareness and understanding puts their health at risk.

The subject of sexual intercourse is generally a taboo in Saudi Arabia. Until late 2012, providing formal sexual education was not introduced in the curriculum of most private and public schools. Most Saudi adolescents discuss sexual-related issues with their friends, and very few discuss them with a parent or maid [4,5]. Reports from a local study conducted on 417 adolescent girls in public and private schools revealed that less than half of the respondents knew that syphilis, gonorrhea, and hepatitis were STIs [5]. In the current study, up to $170(83 \cdot 0 \%)$ of the respondents were not aware of STIs. The major sources of information included friends, television, and radio programs. Given that most of the respondents in our study were mostly expatriates, the poor knowledge on sexual health observed in this study may indicate that Saudi Arabia and countries such as Indonesia, Somalia and Ethiopia are deficient in providing formal education on sexual health.

Appropriate preventive strategies against STIs that conform to Islamic rules and values are necessary, and these should be of the highest priority for policy makers because of the high probability of spread of infection, particularly amongst young adults [14]. Given the annual influx of large numbers of expatriates into Saudi Arabia and the fact that they could be actively involved in the spread of STIs, it is necessary for Saudi authorities to organize campaigns aimed at educating the general population about common STIs and preventive measures.

This study had some limitations in that the study relied on a self-report method of data collection. More so, bias may have been introduced due to intentional deception, poor memory, or misunderstanding of a question or set of questions. It should be taken into account that a relatively large proportion of the study population-one third (34.3\%)-was illiterate, and because the questionnaire was distributed after a lecture, this may have affected the participants' knowledge. Although Saudi women seemed to have better knowledge than expatriate women, we could not deduce relevant conclusions from this fact owing to the limited number of Saudis in our sample. Nevertheless, this study is the first of its kind to examine sexual behaviors and STI knowledge among women inmates at a prison in Jeddah, Saudi Arabia.

\section{Conclusion}

Women inmates at Briman Prison have poor knowledge of STIs as well as risky sexual behaviors. Lack of STI knowledge puts them particularly at risk of acquiring these infections. Campaigns aimed at increasing awareness of STIs should also target prison inmates, who in general constitute high-risk populations. 


\section{Competing interests}

The author declares that they have no competing interests.

\section{Acknowledgements}

I would like to extend my gratitude to Mr. Kalvin Balucanag for performing the statistical analysis on behalf of King Abdulaziz University Hospital.

\section{Funding}

This study was self-funded.

Received: 11 October 2013 Accepted: 14 May 2014

Published: 24 May 2014

\section{References}

1. Kolman M, DeCoster M, Proeschold-Bell RJ, Hunter GA, Bartlett J, Seña AC: The increasing impact of human immunodeficiency virus infections, sexually transmitted diseases, and viral hepatitis in Durham County, North Carolina: a call for coordinated and integrated services. N C Med J 2011, 72(6):439-446.

2. Pedrana A, Hellard M, Guy R, El-Hayek C, Gouillou M, Asselin J, Batrouney C, Nguyen $\mathrm{P}$, Stoovè M: Stop the drama Downunder: a social marketing campaign increases HIV/sexually transmitted infection knowledge and testing in Australian gay men. Sex Transm Dis 2012, 39(8):651.

3. Nakhaee FH: Prisoners' knowledge of HIV/AIDS and its prevention in Kerman, Islamic Republic of Iran. East Mediterr Health J 2002, 8(6):725-731.

4. Fageeh W: Awareness of sexually transmitted diseases among adolescents in Saudi Arabia. JKAU: Med Sci 2008, 15(1):77-90.

5. Alquaiz AM, Almuneef MA, Minhas HR: Knowledge, attitudes, and resources of sex education among female adolescents in public and private schools in Central Saudi Arabia. Saudi Med J 2012, 33(9):1001-1009.

6. Abdelmoneim I, Khan MY, Daffalla A, Al-Ghamdi S, Al-Gamal M: Knowledge and attitudes towards AIDS among Saudi and non-Saudi bus drivers. East Mediterr Health J 2002, 8(6):716-724.

7. Bobrova N, Sergeev O, Grechukhina T, Kapiga S: Social-cognitive predictors of consistent condom use among young people in Moscow. Perspect Sex Reprod Health 2005, 37(4):174-178.

8. Verma RK, Saggurti N, Singh AK, Swain SN: Alcohol and sexual risk behavior among migrant female sex workers and male workers in districts with high in-migration from four high HIV prevalence states in India. AIDS Behav 2010, 14(Suppl 1):S31-S39.

9. Holmes KK, Levine R, Weaver M: Effectiveness of condoms in preventing sexually transmitted infections. Bull World Health Organ 2004, 82(6):454-461.

10. Martin ET, Krantz E, Gottlieb SL, Magaret AS, Langenberg A, Stanberry L, Kamb M, Wald A: A pooled analysis of the effect of condoms in preventing HSV-2 acquisition. Arch Intern Med 2009, 169(13):1233-1240.

11. Paasche-Orlow MK, Clarke JG, Herbert MR, Ray MK, Stein MD: Educational attainment but not literacy is associated with HIV risk behavior among incarcerated women. J Womens Health 2005, 14:852-859.

12. Binson D, Dolcini MM, Pollack LM, Catania JA: Data from the National AIDS Behavioral Surveys: IV: multiple sexual partners among young adults in high-risk cities. Fam Plann Perspect 1993, 25:268-272.

13. Asres B, Yifru B: A meta-analysis on higher-risk sexual behavior of women in 28 third world countries: scientific research. Open Access 2012, 2(2):78-88. doi:10.4236/wja.2012.22011.

14. Madani TA: Sexually transmitted infections in Saudi Arabia. BMC Infect Dis $2006,6: 3$

15. Hong $Y$, Fang $X$, Zhou Y, Zhao R, Li X: Factors associated with sexually transmitted infection underreporting among female sex workers in China. J Womens Health (Larchmt) 2011, 20(1):129-136.

doi:10.1186/1471-2334-14-290

Cite this article as: Fageeh: Sexual behavior and knowledge of human immunodeficiency virus/aids and sexually transmitted infections among women inmates of Briman Prison, Jeddah, Saudi Arabia. BMC Infectious Diseases 2014 14:290.

\section{Submit your next manuscript to BioMed Central and take full advantage of:}

- Convenient online submission

- Thorough peer review

- No space constraints or color figure charges

- Immediate publication on acceptance

- Inclusion in PubMed, CAS, Scopus and Google Scholar

- Research which is freely available for redistribution

Submit your manuscript at www.biomedcentral.com/submit
Ciomed Central 